\section{Are Your Technical Journals an \\ Endangered Species?}

\section{Garry W. Warren and Kebede Gessesse}

Reprinted with permission from JOM (formerly JOURNAL OF METALS) Vol. 47 (1995), pp. 12--3, a publication of The Minerals, Metals \& Materials Society, Warrendale, Pennsylvania 15086.

\section{Introduction}

Greetings from your librarian. Due to severe financial constraints in our budget and price increases significantly higher than inflation, we must cancel as many journal subscriptions as necessary to achieve a reduction in expenses of at least $\$ 500,000$. Your assistance in identifying journals for cancellation will be appreciated.

This was the gist of a memorandum circulated to the faculty at the University of Alabama in 1992. The most expensive journals (i.e., technical, scientific journals) were prime targets for cancellation. From discussions with colleagues at other insti- tutions and research laboratories, it became apparent that similar efforts were underway across the U.S. Trimming the fat is always productive, but reductions of the magnitude mentioned above represent amputations of muscle and bone. Ironically, we considered ourselves lucky to be able to limit the actual reduction in subscriptions to roughly half of those anticipated.

With each budget year and renewal period, an increasingly vicious circle is created, as indicated by Barchall, "When libraries are forced to cancel subscriptions, publishers have to raise prices, forcing libraries to cancel more subscriptions." 1 This undoubtedly has a bearing on the results of a recent study of journal pricing by the Association of Research Libraries that indicated "price increases cannot be attributed to increases in pub-

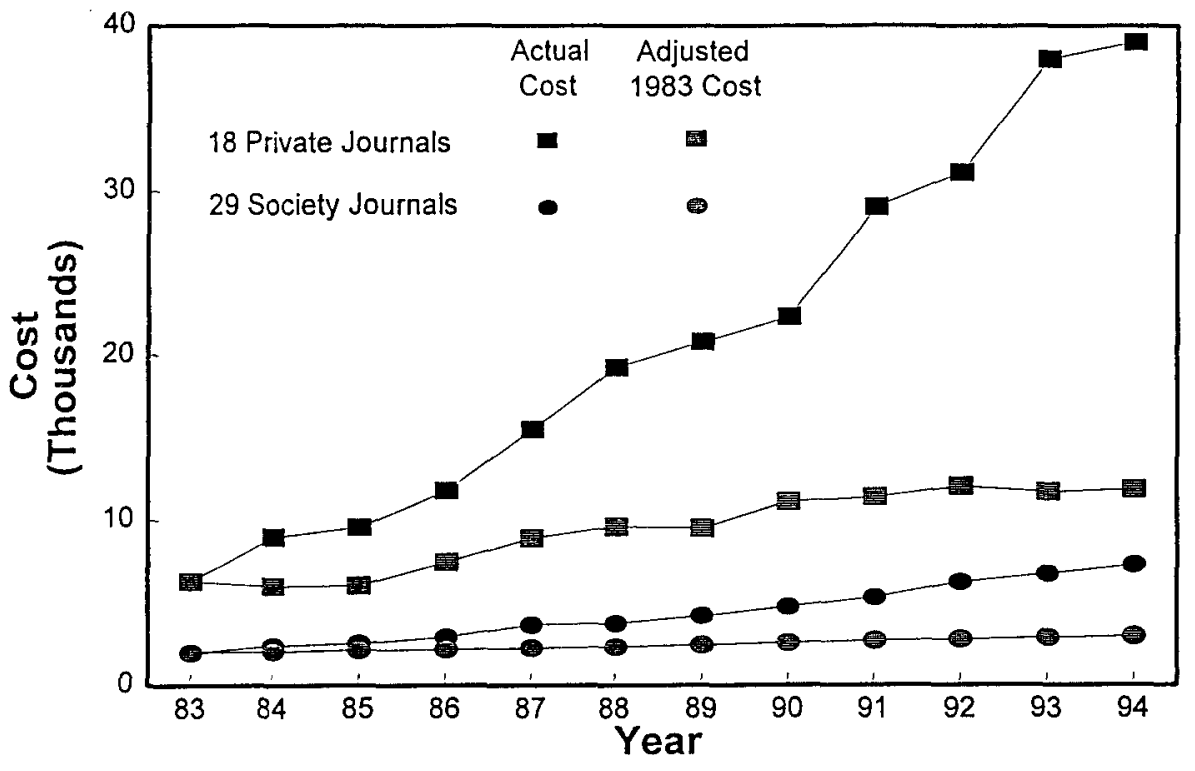

Figure 1. Actual cost of 29 professional society published journals versus 18 private (commercial) journals over the last eleven years. Adjusted cost was calculated using the inflation and exchange rate given in Figure 2 , with the 1983 cost as a basis. lishers' costs." 2 Although the situation has improved temporarily, price increases above the rate of inflation are still the rule rather than the exception.

\section{Characterizing the Problem}

A well-stocked library that includes critical journals in one's chosen field is frequently taken for granted by engineers and researchers, both in academic environments and industrial research laboratories. What many people are not aware of is that the major portion of the acquisitions budget for most (university) libraries is devoted to the purchase of journal subscriptions, each of which generally represents a decades-long commitment to keep that particular journal on the shelf. Maintaining such service becomes increasingly difficult given substantial increases in subscription rates and the number of journals being published. In the past, most engineering professionals have not concerned themselves to any significant degree in the selection and purchase of such journals, except, perhaps, to request particular journals of interest. The time has come, however, for the engineering community to recognize that the cost of journal subscriptions has a direct impact on the availability of technical journals.

Undoubtedly, the publishing world has changed more in the last ten years than the previous fifty. And looking ahead, electronic publishing promises change of even greater significance, even though electronic access to journals is still in its infancy. In our opinion, the technological advances in electronic communication are unlikely to yield significant cost reductions to journal subscriptions in the near future. For the short term, our primary access to the technical literature will continue to be through hard copies of journals.

Many factors affect journal subscription costs, including inflation, page charges, pages published, and currency exchange rates. The latter factor particularly affects private journals since most are published overseas. Page charges are more typical of journals published by professional societies; privately published journals rarely require such fees. Other considerations include number of words per page as well as the inclusion of photographs, illustrations, complex equations, etc. An in-depth analysis of these issues was made for physics journals by Barschall. ${ }^{1,3}$ Barschall noted the same trend indicated in Figure 1 (i.e., privately published journals cost significantly more). In Barschall's case, this conclusion was much the same regardless of whether the basis for comparison was the actual subscription cost, the cost per 1,000 characters, or the cost-to-impact 
ratio (impact was determined by the frequency with which a journal's articles were cited). ${ }^{1,3}$

\section{Private versus Society Journals: A Cost Analysis}

A cursory review of journal subscriptions in the University of Alabama's library immediately showed an obvious and large cost difference between journals published by professional societies and commercial publishing houses. This observation led to a more detailed cost comparison of selected journals for the period 1983 to 1994.

Rather than restrict our analysis to any one discipline, we included journals from six engineering fields although our selection was somewhat weighted toward metallurgical and materials engineering. As shown in Table I, we sought a similar distribution of journals published by both professional societies and commercial publishers. Titles were selected with no prior knowledge of cost. To some extent, we focused on journals that could be found in our library, since cost data were easily available, but other journals were also included. The titles selected are generally recognized to be desirable places to publish, according to faculty colleagues in each of the disciplines. All costs used were either the actual cost to the library or the institutional subscription rate quoted by the publisher or subscription service.

The cost of each journal subscription was tabulated for each year from 1983 through 1994, except for four journals where data began in either 1986 or 1987. The results of this cost analysis are plotted in Figure 1. Clearly, the cost of privately published journals is significantly higher than those published by professional societies. In 1983, the cost differential was already significant, about $\$ 4,500$; by 1994 the differential had grown to more than $\$ 25,000$. This translates to an average annual rate of increase of $16.4 \%$ and $6.3 \%$ for private and society journals, respectively. The annual rate of inflation (based on the U.S. consumer price index [CPI]) for the same period is given in Figure 2 and yields an average of 3.8\% from 1984-1993. Based on the fact that two of the largest private publishers of technical journals (now merged) have been based in the Netherlands (Elsevier) and the United Kingdom (Pergamon), the annual percent change in the exchange rates for the Dutch guilder and British pound are also shown.

Using the data in Figure 2, an adjusted cost for the two journal categories is also shown in Figure 1. This adjusted cost was calculated using 1983 as a basis and adjusting it sequentially, year by year, for corre-

\section{Table I. Journals Selected for Cost Analysis}

(29 published by professional societies and 18 published by private sources).

Published by Professional Societies

Metallurgical \& Materials Engineering Metallurgical Trans. A (TMS/ASM)

Metallurgical Trans. $B$ (TMS/ ASM)

1. Materials Research (MRS) ${ }^{\mathrm{a}}$

J. Electronic Materials (TMS/IEEE)

ACI Materials Journal (ACI)

Applied Optics (AIP)

Corrosion (NACE)

Chemical Engineering AIChE Journal ${ }^{\mathrm{b}}$

Industrial \& Engr Chemistry $(A C S)^{c}$

J. Chemical \& Engr Data (ACS)

Mechanical Engineering

J Engr Materials $\mathcal{E}$ Technol (ASME)

J Appl Mechanics \& Tech Phys (ASME)

J Heat Transfer (ASME)

Mineral Engineering

Mining Engineering (SME)

Electrical Engineering

IEEE Trans on Industrial Applications

IEEE Trans on Magnetics

IEEE Trans on Computers

IEEE Trans on Power Systems

Civil Engineering

Civil Engineering (ASCE)

J American Water Works Assn.

\section{Privately Published}

Elsevier

Journal of Nuclear Materials

Materials Science \& Engineering $A^{\mathrm{a}, \mathrm{d}}$

Materials Science \& Engineering $B$

Nuclear Instruments $\mathcal{E}$ Mthds in Physics-B

Surface Science

Int'l J Mineral Processing

Wear

Pergamon

Acta Metallurgica

Chemical Engineering Science

Int'l J Heat \& Mass Transfer

Scripta Metallurgica

$J$ Applied Math $\mathcal{E}$ Physics of Solids

J Mechanics \& Physics of Solids

Canadian Metallurgical Quarterly

Other Private Publishers

J Magnetic Resonance (Head)

J Materials Science (Chapman \& Hall) ${ }^{c}$

$J$ Polymer Science (Wiley)

J Engineering Mathematics (Kluwer)

a1986-1994 only

$b^{b}$ cost also includes 9 other AIChE journals

'1987-1994 only

${ }^{d}$ split into Sections A \& B in 1988

sponding changes in exchange rates (based on the publisher's home country) and inflation (based on the U.S. CPI). An inflation estimate of $3 \%$ was assumed for 1994. It should be pointed out that inflation rates in Europe may be higher than those shown in Figure 2. However, even if the adjusted cost is calculated using inflation rates three times higher than those shown in Figure 2, the resulting adjusted cost of the 18 private journals in 1994 is $\$ 23,000$, which is significantly smaller than the actual cost of $\$ 39,000$. These data indicate that the large price increases observed for the private journals cannot be attributed to inflation or a steady decrease in exchange rate of the dollar versus other currencies. This view is supported by the study of serials pricing performed by the Association of Research Libraries. ${ }^{2}$

\section{The Search for a Solution}

You might ask, what about electronic publishing? Can such technology solve this problem? Electronic publishing via CD-ROM (compact disk/read-only memory) and/or the highly touted "information superhighway" is very desirable and probably inevitable; however, complete and effective implementation is still years away. Much progress has been made regarding the digital submission of manuscripts but problems remain. For example, many symbols and mathematical equations may often require manual handling. There are somewhat fewer problems with graphics, but conversion from one graphics format to another can be troublesome. Furthermore, many thorny logistical and legal issues are unresolved. Copyright is particularly difficult (e.g., what exactly constitutes a copy, who pays, and how much?).

A number of issues are typically considered to have a major impact on journal cost, including a relative lack of competition among private publishers, the explosion in the number of new journals and the total number of pages published, and a downward trend in the number of journals published by societies.

What, if anything, can we as scientists, engineers, and members of professional societies do to affect these issues? Clearly we can no longer divorce ourselves from the question of journal costs since this has a direct impact on both the availability of the technical literature we require and on the dissemination of our own research results. We should also begin to ask whether we should publish research results in journals that our own libraries cannot afford.

We must also seriously question the need for each new journal that is proposed. Granted, new journals in a rapidly changing technical environment may be necessary, but only after careful scrutiny and a concerted effort to avoid duplication. In some cases, this could result in a refusal to participate on the board of review or to submit papers for publication. Obviously, we should make plain our reasons for such refusal. A well-reasoned case could be made that profes- 

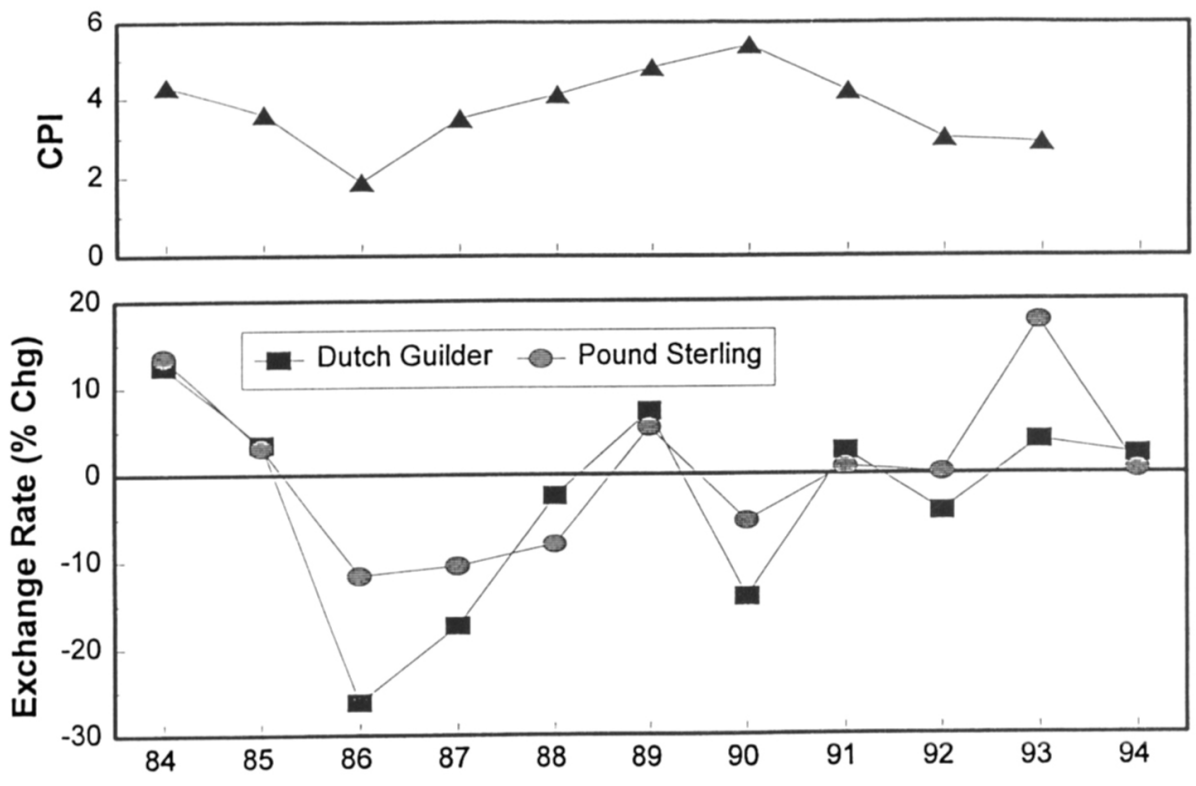

Figure 2. Percent change in U.S. consumer price index and exchange rates (source: Employment Coordinator, June 1994, and 1994 World Almanac, respectively). an interest in working with scholars to influence the amount of information published and its distribution.

As individual scientists, engineers, and information specialists, we have only two choices; either we must attempt to influence this process or live with a situation imposed by others. At stake may be your library's access to the technical literature that you require to perform your job.

\section{References}

1. H.H. Barschall, Phys. Today 41 (1988) pp. 56-59.

2. O. Ivins, Serials Rev. 15 (1989), pp. 53-55.

3. H.H. Barschall, Phys. Today 34 (1986) pp. 34-36.

Garry W. Warren is a professor of metallurgical and materials engineering at the University of Alabama, Tuscaloosa. Kebede Gessesse is head of reference services and circulation at Rogers Library for Science and Engineering at the University of Alabama. sional societies are in a much better position than other organizations to determine the need for new journals.

In earlier times, most technical journals were published by professional societies rather than private publishers. Professional societies have reduced such activities for many reasons-lack of personnel and cost are among them. Perhaps now is the time for professional societies to reconsider this issue.

The question of page charges would be one component of the discussion. A complete analysis of the relationship between page charges and journal cost is beyond the scope of this article, but Barschall found that for several physics societies, income from page charges can vary from as little as $10 \%$ to as much as $50 \%$ of the journal budget. ${ }^{3}$ As distasteful as page charges may be to some prospective authors, the alternative may be even more irksome. The current situation suggests that authors who intentionally avoid page charges by publishing in private journals may actually be paying more for their journals via increased library subscriptions.

Initiating a dialogue with the Association of Research Libraries would also seem worthwhile, as they have indicated

Material Matters is a forum for expressing personal points of view on issues of interest to the materials community.

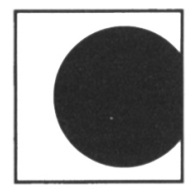

\section{S T A I B INSTRUMENTE \\ 813 Diligence Drive - Suite 121.E - Newport News Va 23606 . Phone 8048730009 - Fax 8048730130}

Obere Hauptstraße 4585354 Freising Germany Tel. +(49)8161-7740 Fax -7709

\section{RHEED SYSTEMS $35 \mathrm{keV}, 20 \mathrm{keV}$, $12 \mathrm{keV}$}

RHEED VISION

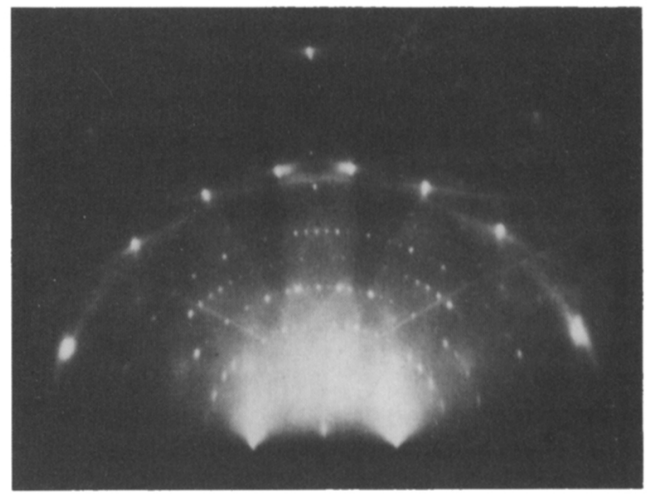

\section{Precision RHEED SYSTEMS}

* energy from 1 to $35 \mathrm{keV}$

* high beam current and stability

* lowest divergence

* remote controls

* Beam Blanking

* Beam Rocking

* differential pumping

* computer interface

* diagnostic port logic for fast technical customer support by Fax

\section{RHEED VISION}

* high speed CCD camera acquisition systems

* RHEED oscillations on several spots simultaneously

* dynamic multiple line scans

* dynamic multiple spot profiling

* 8 and 16 bits image processing

* comfortable data transfer and networking 


\section{A Prime Investment Buy 2 to 5 Silicon Membranes at VSI's 100 Rate}

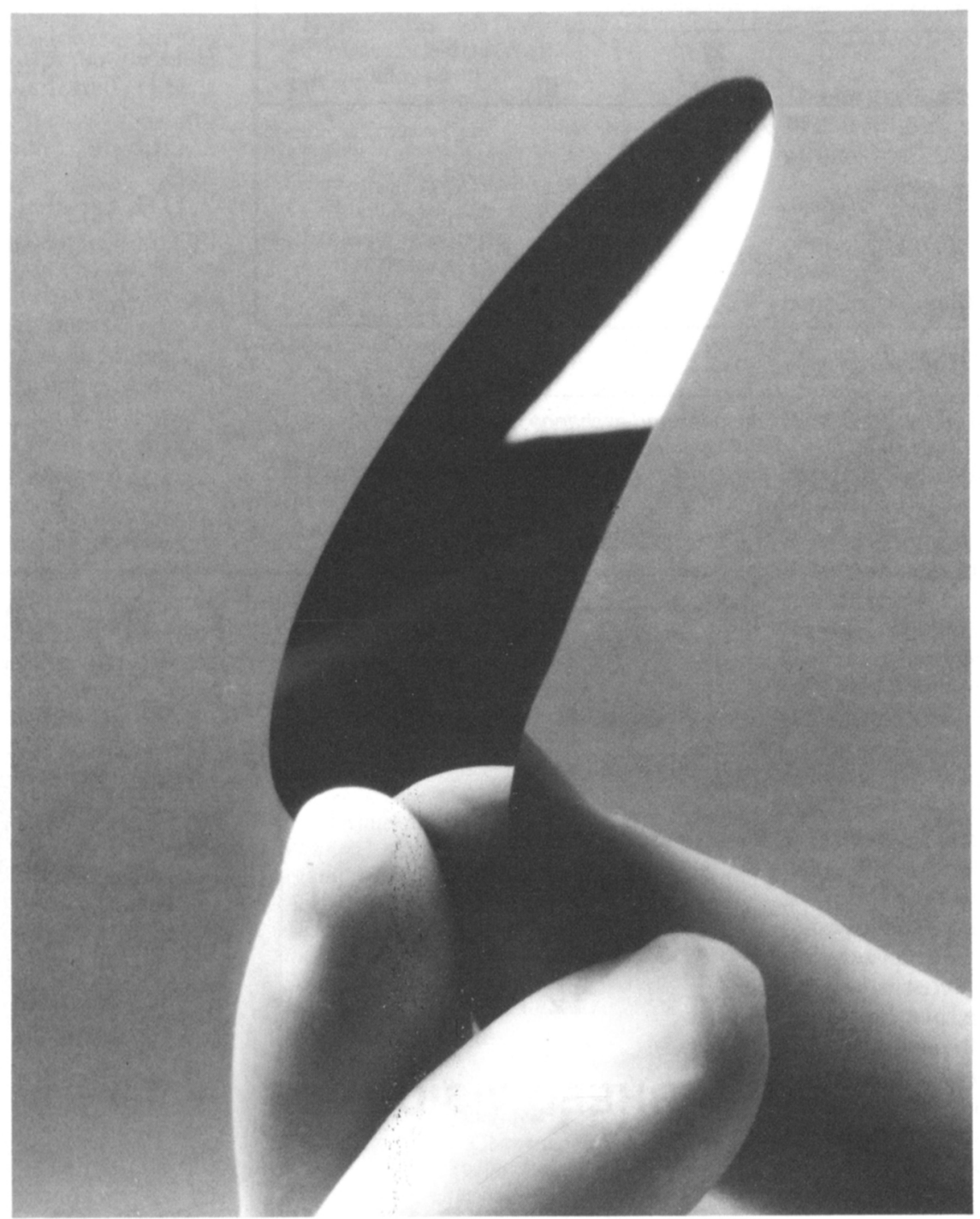

Virginia Semiconductor, Inc. is aware that the purchase of Ultrathin ${ }^{\mathrm{TM}}$ silicon membranes can be an expensive investment.

This winter, VSI will be collecting orders, large and small, that fall within a common range. Combined batches will then be processed together. Prices for all orders will be based on VSI's 100 wafer purchase rate. For customers buying 2 to 5 Ultrathin $^{\mathrm{TM}}$ silicon membranes, that is a $50 \%$ savings.

To place an order or receive additional information, please telephone, fax, or mail Virginia Semiconductor, Inc. . To guarantee these savings, place your order by April 28, 1995

VIRGINIA SEMICONDUCTOR, INC.

Phone (703) 373-2900 Fax (703) 371-0371 